\title{
Laudation for Professor Susanta Lahiri Hevesy Medal Awardee 2015
}

\author{
A. Chatt ${ }^{1}$
}

Published online: 27 January 2016

(c) Akadémiai Kiadó, Budapest, Hungary 2016

Susanta Lahiri was born in Darjeeling, India, in 1961. He received his $\mathrm{PhD}$ (1994) from the University of Calcutta. In the same year he started his career as a lecturer (Assistant Professor) in Chemistry at the University of Burdwan, India. He moved to the Saha Institute of Nuclear Physics in 1997 where he became a Professor in 2003 and a Senior Professor in 2013. He is also a Professor at Homi Bhabha National Institute, Bhabha Atomic Research Centre in Mumbai, India.

Professor Lahiri's work is associated with many "firsts". In his early career, he started cyclotron production of no-carrier-added (NCA) radionuclides by alpha particle activation. Prof. Lahiri was the first scientist to irradiate lanthanide targets by heavier projectiles like ${ }^{7} \mathrm{Li},{ }^{11} \mathrm{~B},{ }^{12} \mathrm{C}$, ${ }^{16} \mathrm{O}$ etc. which made access to neutron deficient short-lived radioisotopes easier and expanded the horizon of clinically important radionuclides. He introduced the "tracer packet" idea, which allows one to deal with many similar radioactive tracers at-a-time in one experiment rather than setting up many experiments with individual tracers. His group is developing a number of green chemistry radioanalytical methods based on aqueous biphasic systems and room temperature ionic liquids. His group reported the first green chemistry synthesis of radioactive gold nanoparticles by adding $\mathrm{H}^{198} \mathrm{AuCl}_{4}$ to polyethylene glycol. Professor Lahiri and his colleagues also joined the TASCA group in GSI, Germany. Recently they independently confirmed E-117. Neutrino mass measurement is a burning problem

A. Chatt

chatt@dal.ca

1 Department of Chemistry, Trace Analysis Research Centre, Dalhousie University, 6274 Coburg Road, Room 212, P.O. Box 15000, Halifax, NS B3H 4R2, Canada of fundamental science. Professor Lahiri's team, for the first time, proposed indirect production route of ${ }^{163} \mathrm{Ho}$ via ${ }^{n a t} \mathrm{Dy} /{ }^{163} \mathrm{Er}$ and ${ }^{159} \mathrm{~Tb} /{ }^{163} \mathrm{Er}$ reactions to increase the yield of ${ }^{163} \mathrm{Ho}$ by orders of magnitude to help neutrino studies.

He carried out most of his basic Nuclear Chemistry work using medium energy accelerators in Mumbai and Kolkata and complemented it by collaborating with international institutions such as CERN, GSI, Heidelberg University, Institute of Modern Physics in China, TU Munich, ATOMKI Hungary, TU Delft, ETH Switzerland, and others. His team for the first time unveiled the total radionuclide inventory produced by bombardment of 1.4 $\mathrm{GeV}$ proton on thick lead-bismuth target.

In a nutshell, Prof. Lahiri's wide research interest is reflected in about 190 publications in international journals, and 250 reports in international and national conferences. $\mathrm{He}$ made contributions in ten books. He has received several national and international awards. He is a member of distinguished reviewers' board of JRNC since 2005. He has supervised $11 \mathrm{PhD}$ and $26 \mathrm{MSc}$ theses so far. In recognition of his contribution in Nuclear Chemistry, The University of Calcutta conferred the highest academic honor, namely DSc degree, upon him in 2009. The title of his DSc dissertation was "Production and separation of carrier free radionuclides". Recently Indian Chemical Society bestowed him "Acharya J. C Ghosh Memorial Award" for the year 2014.

It is indeed a pleasure to honor Prof. Susanta Lahiri with the Hevesy Medal Award 2015 for his outstanding contributions on heavy ion induced radioisotope production, tracer packet technique, converter targets, and green chemistry.

The Hevesy Medal Award Selection Panel 2015 (HMASP-15) consisted of Professor Amares Chatt (Dalhousie University, Canada; also Chair of JRNC Board of 
Fig. 1 From left to right Dr. Tibor Kocsor, Dr. Zsolt Revay, Prof. Susanta Lahiri, Prof. Amares Chatt, Dr. Sam Glover, and Dr. Stephen Lamont

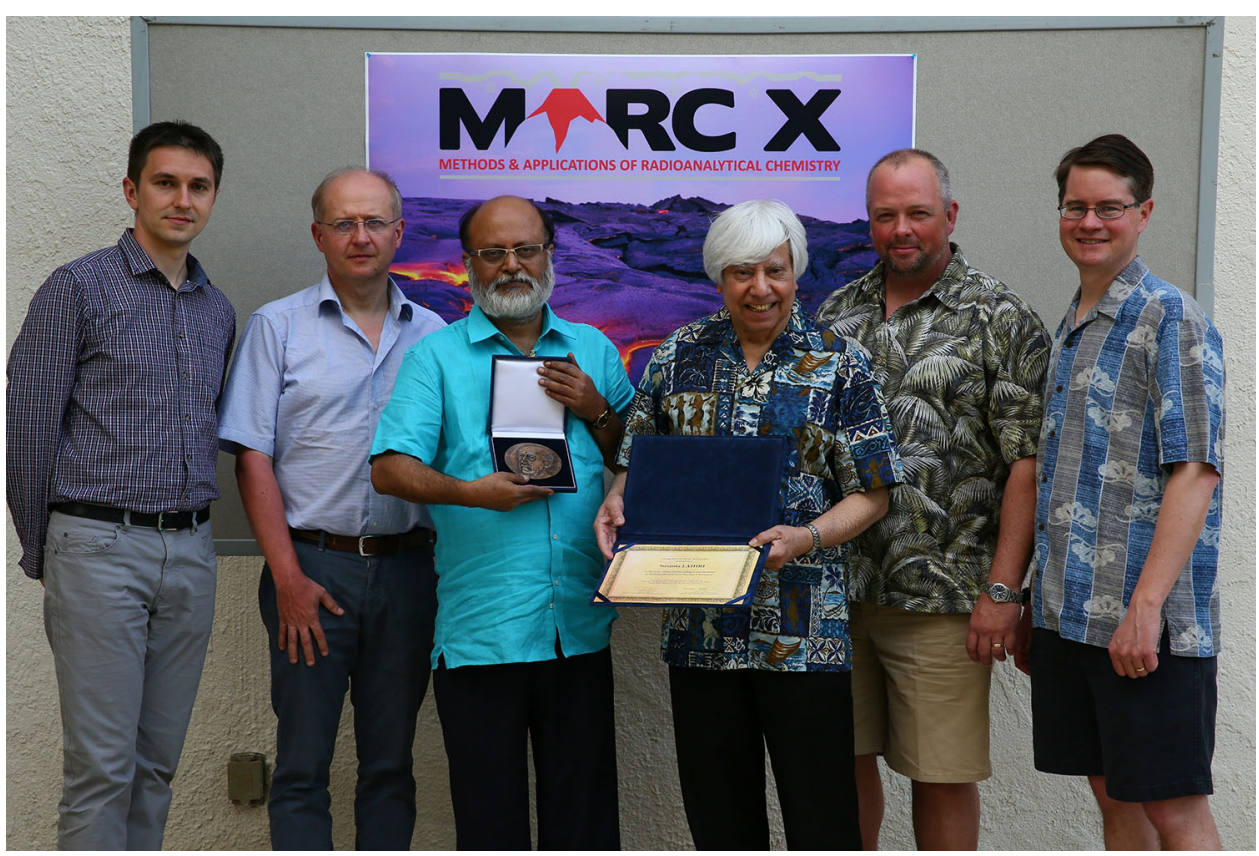

the Hevesy Award, and Chair of HMASP-15), Dr. Peter Bode (Delft University of Technology, The Netherlands; also representing MTAA-14), Professor Chai Zhifang (Chinese Academy of Sciences, China), Dr. Sam Glover (National Institute for Occupational Safety and Health, U.S.A.; also representing MARC-X), Professor Jan John (Czech Technical University in Prague, Czech Republic), Dr. Richard M. Lindstrom (National Institute of Standards and Technology, U.S.A.), Professor Boris F. Myasoedov (Russian Academy of Sciences, Russia), Professor Syed
Qaim (Forschungszentrum Juelich GmbH, Juelich, Germany), and Dr. Zsolt Revay (Technische Universität München, Germany; also representing JRNC). In accordance with the rules of the Award, a secret vote was conducted.

The Hevesy Medal and a scroll were presented to Professor Lahiri at the Tenth International Conference on Methods and Applications of Radioanalytical Chemistry (MARC-X) held in Kona, Hawai'i, U.S.A. during 2015 April 12-17 (Fig. 1). 